\title{
Dry Deep Drawing of Aluminum and the Influence of Sheet Metal Roughness
}

\author{
FELIX FLEGLER, ${ }^{1,3}$ PETER GROCHE, ${ }^{1}$ TIM ABRAHAM, ${ }^{2,4}$ \\ and GÜNTER BRÄUER ${ }^{2}$ \\ 1.-Institute for Production Engineering and Forming Machines (PtU), Technical University of \\ Darmstadt, Otto-Berndt-Straße 2, 64287 Darmstadt, Germany. 2.-Fraunhofer Institute for \\ Surface Engineering and Thin Films IST, Bienroder Weg 54 E, 38108 Braunschweig, Germany. \\ 3.—e-mail: flegler@ptu.tu-darmstadt.de. 4.—e-mail: tim.abraham@ist.fraunhofer.de
}

\begin{abstract}
Dry forming processes are associated with major challenges, especially when it comes to aluminum as the workpiece material. Major losses in process quality and robustness occur when lubricants are spared. This is due to the high adhesion tendency of aluminum towards common tool materials. Nanoscopically smooth coatings based on amorphous hydrocarbons (a-C:H) can significantly reduce wear. Further preliminary investigations have shown that a reduction of the roughness of a mill-finished sheet results in a significant improvement with regard to the friction and wear behavior in the strip drawing test. These tests are now transferred to a real workpiece. First, the different zones of the deep drawing process are modeled in the strip drawing test and coefficients of friction are derived. Flawless deep drawing tests can be carried out with nanoscopically smooth a-C:H coatings. By polishing the sheets and using the a-C:H coated tools without further surface treatment, the dry friction and wear are reduced, but compared with experiments on smoothened a-C:H coatings, the necessary process forces are higher and may lead to rupture of the aluminum sheet.
\end{abstract}

\section{INTRODUCTION}

Due to its outstanding capacity to absorb energy and enormous lightweighting potential, aluminum is used in various automotive and aerospace applications. However, its pronounced adhesion tendency when in contact with other materials leads to challenges in aluminum forming processes. ${ }^{1}$ Currently, these adhesion tendencies are counteracted by lubrication, which helps to stabilize the forming process and guarantee the required part quality. Extensive lifecycle assessments available for machining processes in general report a negative impact of lubricants on the sustainability of production processes. ${ }^{2-4}$

The results of these impact analyses increase the pressure on the forming industry to overcome the sustainability issues and develop alternative methods for less toxic aluminum forming. Furthermore, the process chain in sheet metal forming often includes a subsequent cleaning of the formed parts, for example, to ensure good adhesion of a lacquer coat or prevent contamination of other contacting materials. Lubricants account for this additional process or at least complicate the cleaning method. A sophisticated lifecycle assessment of metal forming applications should consider these negative factors, which significantly worsen the environmental impact of lubricants on manufacturing processes. Thus, the utilization of dry sheet metal forming is a useful approach to improve the sustainability of aluminum products. However, surrendering the usage of lubricants leads to rapid formation of aluminum adhesion on the tool surface and often immediate tool failure. Consideration of the relevant wear mechanisms and influencing parameters can help with the development of effective strategies to improve the tribological conditions in a dry steel-aluminum contact. By eliminating lubricants, a significant increase in the sustainability of forming processes seems possible. However, wear mechanisms need to be understood and parameters identified to ensure a stable process for dry forming aluminum. 
Within the Priority Program 1676 of the German Research Foundation entitled "Dry Forming," various approaches for dry deep drawing processes were generated; For example, by selective oxidation of the die surface, a significant reduction of the coefficient of friction in dry deep drawing has been achieved. ${ }^{5}$ In addition, the micro- and macrostructures of the die surface show a further reduction of friction and wear. ${ }^{6}$ Subsequent painting and coating processes are susceptible to remaining lubricants, which can affect the adhesion of subsequent coatings. Liewald et al. are therefore pursuing the approach of lubrication with self-evaporating media such as $\mathrm{CO}_{2}$ and $\mathrm{N}_{2}{ }^{7}$

Research has furthermore shown promising results when thin hard films are applied on tools to minimize friction coefficients and optimize the wear conditions in the forming process. A subclass of the amorphous hydrogenated carbon coating (a-C:H), viz. diamond-like carbon (DLC), is well known for its excellent tribological properties. ${ }^{8}$ The high density of this coating ensures high wear resistance and leads to a low friction coefficient. Additionally a low adhesive tendency in contact with aluminum has been observed. ${ }^{9-11}$ Research outcomes suggest that the self-lubrication tendencies of the a-C:H coating contribute to its low tendency for adhesion. ${ }^{12}$ However, coated tools still show quick adhesion in aluminum forming, like their uncoated counterparts. ${ }^{13}$ First experiments suggested an unfavorable run-in behavior of a-C:H coatings as the reason for this rapid adhesion. ${ }^{13}$ This run-in behavior can be described as a short period at the beginning of the sliding contact. This behavior is further characterized by high friction values and a tendency for adhesion. After the run-in period, a smoother surface can be observed. This can most likely be traced back to nanoscopic abrasion. Westlund et al. investigated the interaction between the nanoscale smooth a-C:H surfaces and their adhesion tendency. ${ }^{14}$ They concluded that exceptionally smooth surfaces have a positive influence on the adhesion in dry forming of aluminum. That research indicated a possible way to eliminate lubrication and allow for true dry metal forming. In addition to the tool surfaces, the properties of the sheet metal also play a decisive role in dry forming. Flegler et al. presented the influence of the sheet roughness and associated contact area of the nearsurface structures on the adhesive wear behavior. The results revealed that, by polishing the sheet surface to values of $R_{z}$ less than 0.3 with a uncoated, polished tool surface, the adhesive wear could be reduced by $90 \% .{ }^{15}$ The increased contact area of the surface results in smaller deformations of the roughness peaks. Consequently, the protective oxide layer of the aluminum remains intact longer and prevents adhesive wear on the tool. In addition to wear, the friction at the drawing radius could also be significantly reduced, which makes the use of this approach in a deep drawing process promising. Subsequent investigations evaluated various surface finishes with regard to their coefficient of friction in the typical friction zones of a deep drawing process and enabled a preselection to be made. ${ }^{16}$

In particular, coating the tool with a-C:H with reduced roughness and the use of polished aluminum sheet metal are promising approaches for dry forming of aluminum. In The corresponding deep drawing experiments are presented and analyzed herein. Using a numerical representation, explanatory approaches for the observed phenomena are presented.

\section{MATERIALS AND METHODS}

\section{Materials}

Aluminum EN AW-5083 with a mill-finished surface and sheet thickness of $1.5 \mathrm{~mm}$ was used for the deep drawing experiments. EN AW-5083 is characterized by its self-hardening properties, which lead to high hardness and strength. However, the material cannot be heat treated to improve these parameters further. These properties explain the preferred application of this material in highly loaded welding constructions, e.g., in vehicles, tanks, and apparatus construction. The drawing rings are made of heat-treated 1.2379 work steel, hardened to $60 \mathrm{HRC}$. Prior to coating, the tools are prepolished using a diamond suspension. Table I presents the relevant mechanical properties.

The sheet metal rounds were punched using a tool and the same forming press as used for the deep drawing experiments, thereby guaranteeing full control over the quality and consistency of the cylindrical aluminum blanks. All blanks were punched from the same aluminum sheet, allowing for the assumption of equal properties. For the experiments with polished DLC tools and polished blanks, the blanks were polished manually to $R_{z}=0.287 \pm 0.05 \mu \mathrm{m}$. The roughness of the aluminum sheets was scanned using a confocal microscope ( $\mu$ Surf). A magnification of 50 was used to obtain the surface roughness values at three different spots on the sheet metal. The measurement was done for only one polished blank. Previously manually polished material of the same kind shoed a reduction of the friction coefficient from 0.4 to 0.11 as described by Flegler et al. ${ }^{15}$ The burr on all the blanks after the punching process was removed, and they were lubricated homogeneously on the blank holder side with Wisura AK 3080 oil applied using a roll. This lubrication can be characterized as maximum quantity lubrication.

\section{Coating Deposition and Polishing}

The coating of the tools was conducted at the Fraunhofer IST in Braunschweig using a plasmaassisted chemical vapor deposition (PACVD) process with a mixture of argon and acetylene $\left(\mathrm{C}_{2} \mathrm{H}_{2}\right)$ as precursor gas. Before the deposition process, the parts must be cleaned. This cleaning was done by sputter cleaning for $30 \mathrm{~min}$ prior to coating. To 
Table I. Material properties of sheet metal and tools

\begin{tabular}{|c|c|c|c|c|c|}
\hline Material & Short symbol & $\boldsymbol{R}_{m}(\mathbf{M P a})$ & $\boldsymbol{R}_{p 0.2}(\mathrm{MPa})$ & Material condition & Surface finish \\
\hline EN AW-5083 & $\mathrm{Al} \mathrm{Mg4.5Mn}$ & $>275$ & $>125$ & $\mathrm{O}$ & Mill finish, polished \\
\hline 1.2379 & X153CrMoV12 & 860 & 420 & Hardened & Polished and coated \\
\hline
\end{tabular}
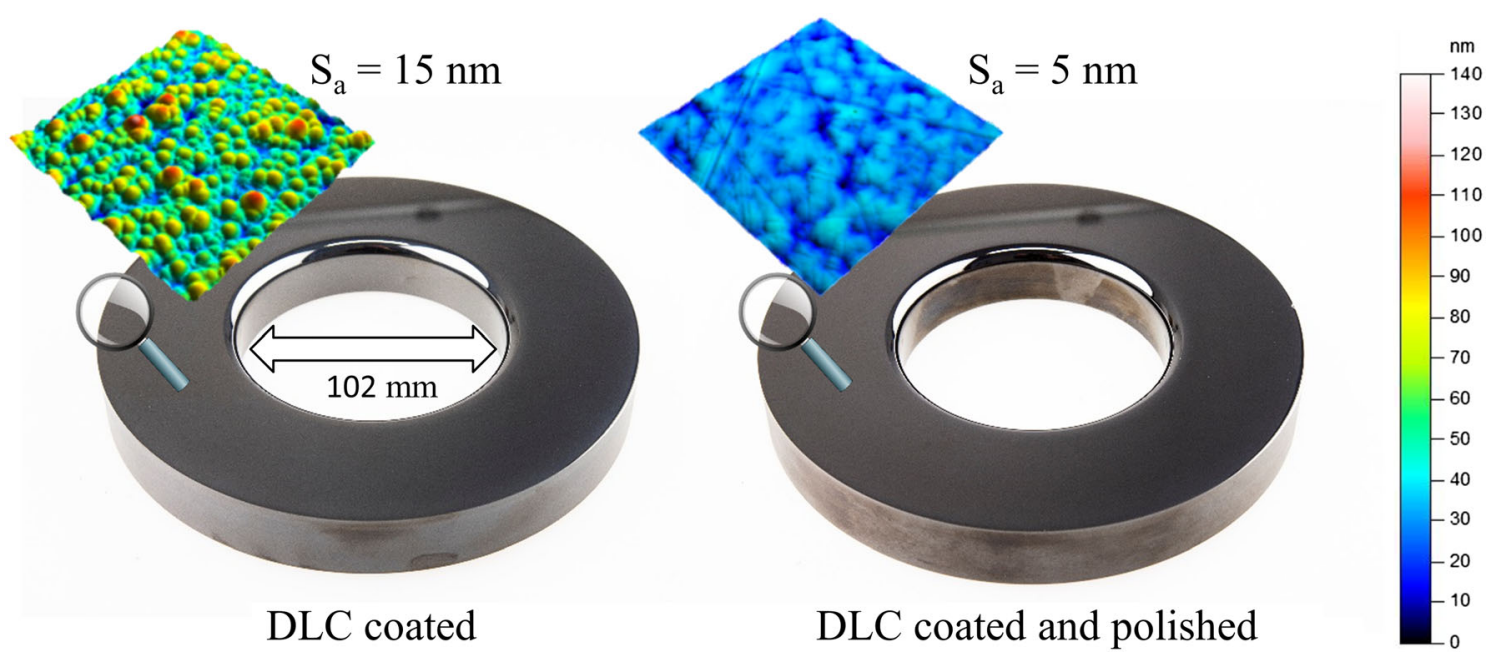

Fig. 1. Coated tools and corresponding surface roughness $S_{a}$ (arithmetical mean height).

ensure the adhesion of the a-C:H coating, an interlayer of titanium with thickness of $0.2 \mu \mathrm{m}$ was applied by magnetron sputtering. The subsequent vapor deposition achieved a coating with thickness of $2.4 \mu \mathrm{m}$. A detailed description of the process and further information regarding the properties of the coating can be found in Ref. 17 . The achieved surface hardness was measured using a Fischerscope H 100 by recording load versus depth curves up to $30 \mathrm{mN}$ measuring $32 \mathrm{GPa}$. A ball cratering test operation with alumina $\left(\mathrm{Al}_{2} \mathrm{O}_{3}\right)$ suspension (mean alumina grain size $1 \mu \mathrm{m}$ ) was used to examine the abrasive wear rate. The analysis yielded an abrasive wear rate of $1.0 \times 10^{-15} \mathrm{~m}^{3} /$ $\mathrm{Nm}{ }^{18}$ The hydrogen content of the coating was measured to be 17 at.\% utilizing secondary-ion mass spectrometry. One of the tools was subsequently polished by hand using $3-\mu \mathrm{m}$ diamond suspension to achieve better wear coefficients. To ensure the cleanliness of the surfaces, the tools were cleaned using acetone and isopropanol prior to use. The coated tools are shown in Fig. 1.

\section{Experimental Setup}

According to the previous investigations, the test matrix presented in Table II was selected.

For the experiments, the DLC-coated tools were installed in the press and the blanks were positioned with the aid of a positioning template. The press was set to a drawing speed of $100 \mathrm{~mm} / \mathrm{s}$ and a maximum blank holder force of $40 \mathrm{kN}$; these parameter values remained unchanged throughout the experiments and replicate production conditions. Between the experiments, the drawing ring was changed and realigned with the blank holder to ensure the same quality for each forming process. The tool was thoroughly inspected after each forming process in order to detect wear on the tool immediately.

The geometric conditions of the process are shown in Fig. 2. The ratio stamp diameter and blank diameter yield a deep drawing ratio of 2.0, which according to Ref. 19 is a relatively high value leading to a very small process window.

\section{NUMERICAL SETUP}

For a better understanding of the forming behavior and the dependence on the friction coefficients obtained from the strip drawing tests, the rotationally symmetric deep drawing process was modeled using a numerical finite-element method (FEM) simulation. A rotationally symmetric model implemented in ABAQUS 2019 was used, assuming isotropic material behavior and evenly distributed sheet edge feed. The tools were modeled as rigid bodies, while the plastic behavior of the sheet material was described by a flow curve derived from a uniaxial tensile test. Since the blank holder side of the tool is lubricated in the real process, different coefficients of friction were defined for the upper and lower sides of the blank and for the different tribological systems according to Table II. The 
Table II. Experimental setup according to Refs. 13, 15, and 16

\begin{tabular}{lccc}
\hline Tool & Sheet metal & Lubrication & Coefficient of friction \\
\cline { 4 - 4 } DLC standard & Mill finish & Maximum & $0.02^{16}$ \\
DLC standard & Polished & Dry & $0.11^{15}$ \\
DLC polished & Mill finish & Dry & $0.07^{16}$ \\
DLC polished & Polished & Dry & $0.07^{16}$ \\
\hline
\end{tabular}
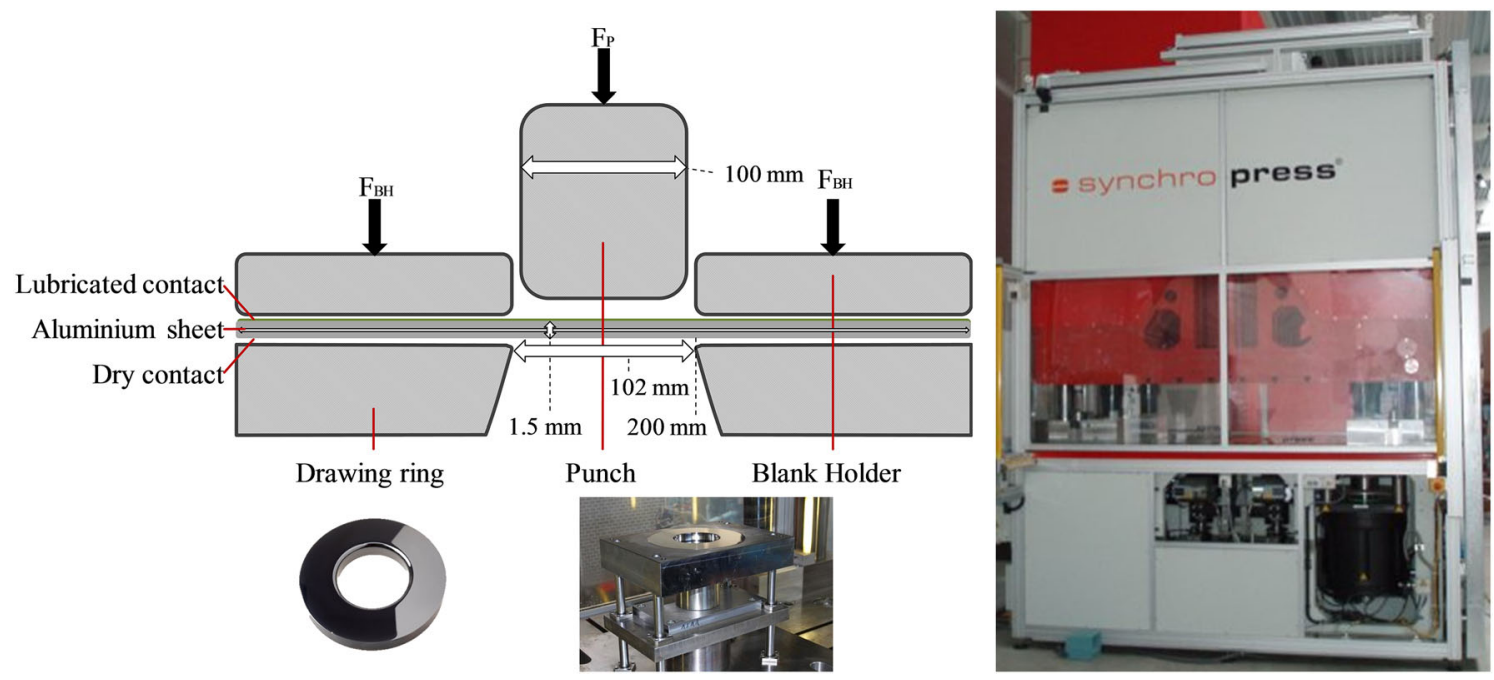

Fig. 2. Geometric conditions of the rotationally symmetric deep drawing process at the PtU.

discretization of the sheet was done using eight elements of type CAX4R in the sheet thickness direction. The blank holder force was set to $40 \mathrm{kN}$ according to the real experiments. All the geometric tool parameters correspond to the real conditions.

\section{RESULTS AND DISCUSSION}

The four different setups showed surprising, partially unexpected results. The DLC-coated and polished tool against mill-finish and polished blanks allowed for more than 53 wear-free recurrences. However, the combination of a standard DLC coating and polished blanks yielded failures, and no part could be produced. The combination with mill-finish blanks and the standard DLC coating only confirmed these failed attempts. The experimental results show a stamping force that suggests a critical load of around $115 \mathrm{kN}$. This load was surpassed by all the failed attempts. Among the 50 successful attempts for the DLC-coated and polished tool, only one measurement showed a load above $115 \mathrm{kN}$. This attempt also failed without leaving wear marks on the tool, supporting the assumption of the given critical load. The overall process window with the given geometric parameters seems very small, and small alterations in friction lead to part failure, as shown in Fig. 3. The results of these experiments are shown in Fig. 4. The error margin on the measurements is presented in the same color as the mean value of the stamping force. The findings of these experiments partly validate the previous assumptions and expectations. The results indicate a greatly increased process stability for the DLC-coated tool with extra polishing and stamping forces just slightly above the maximum lubricated pendant. However, the combination of polished sheet material and standard DLC-coated tool did not show the expected result. Following the experiments, the tools were checked for signs of wear. No evidence of wear was found on the DLC-coated and polished tool, even after all 53 process iterations. The standard DLC-coated tool with polished blanks showed minimal wear.

While the combination of standard DLC tool coatings with polished sheets in the strip drawing test provided promising results in terms of wear, the deep drawing tests were unsuccessful. The expected coefficient of friction in the area of the blank holder was significantly higher with this combination than with the use of a polished DLC coating. The higher friction in the area of the blank holder results in higher retention forces, so that material failure can occur earlier, and a cup that is not fully formed is the result. To confirm this hypothesis, the numerical model described in "Experimental Setup" 


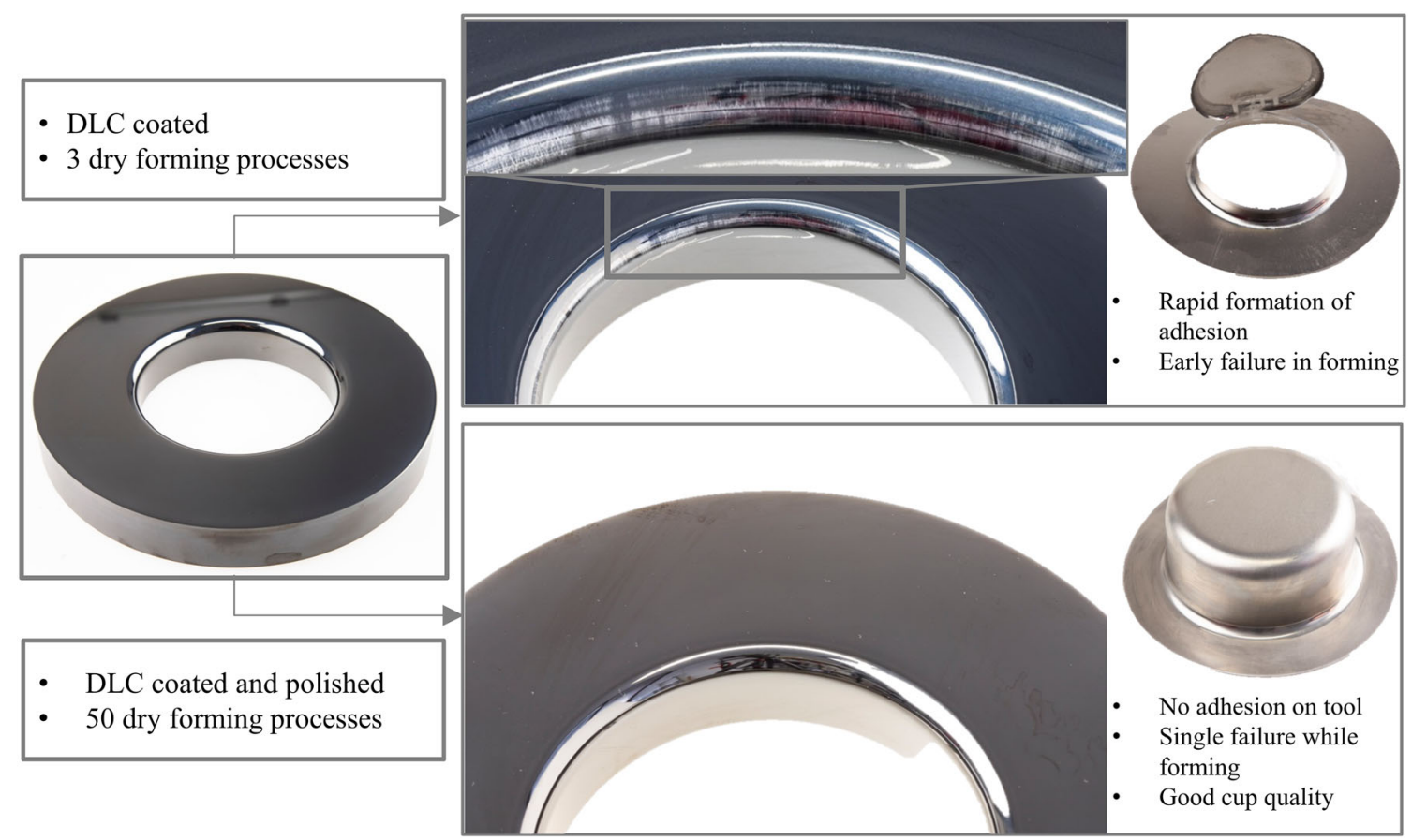

Fig. 3. Tools and produced parts after the experiments. The DLC-coated and polished tool showed no signs of wear, while the standard DLCcoated tool showed wear marks at the drawing radius.

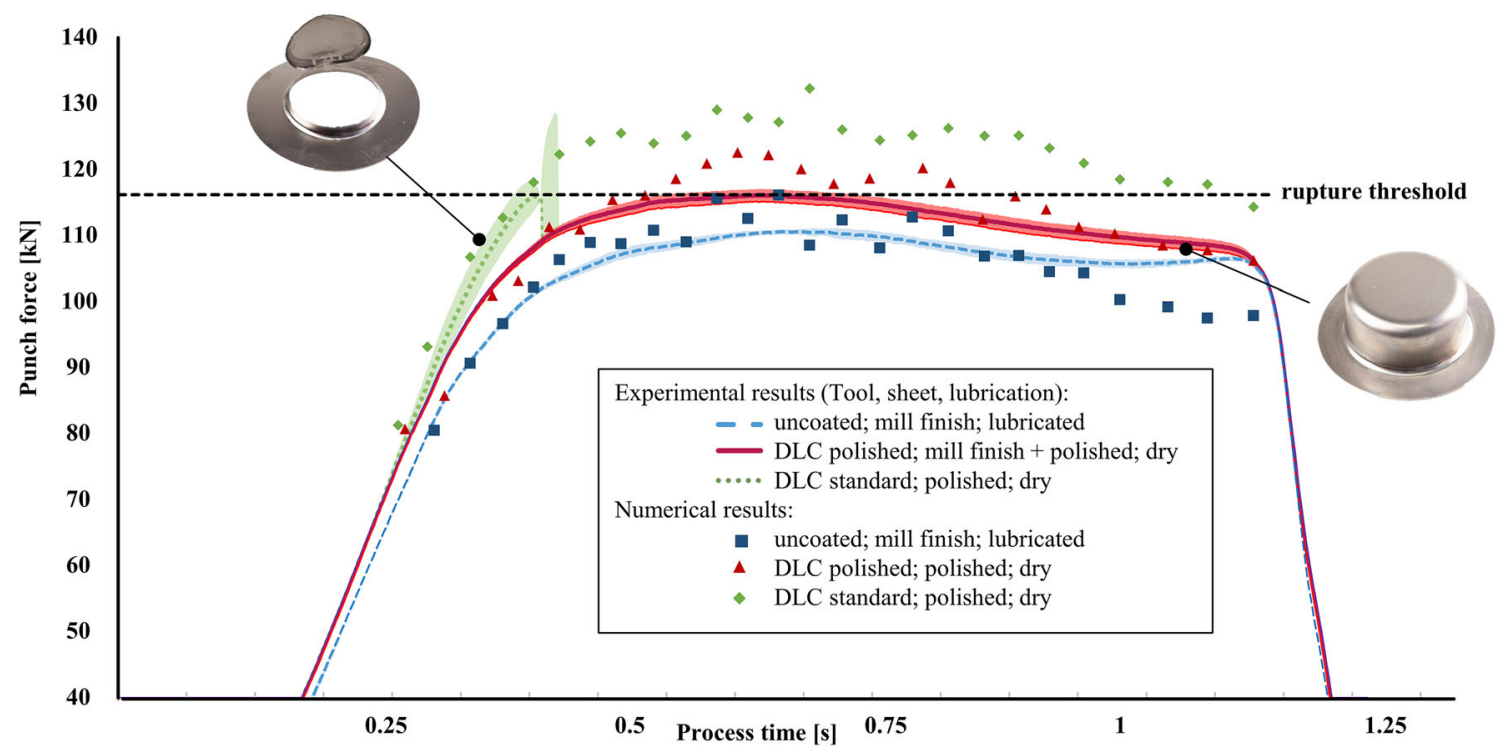

Fig. 4. Stamping force data derived from the experiments and the equivalent numerical representation.

section was used and evaluated for the different tribological systems. As shown in Fig. 4, the maximum force of the lubricated reference process was on average very well met. The strong fluctuation of the simulated values is due to numerical inadequacies of the model. The explicit simulation and contact formulation results in an oscillation of the force values around a mean value. The data were not smoothed, and instead individual points of this oscillation were taken and displayed. For this reason, the graph shows an increased scatter of the numerical results. The maximum force during forming is around $110 \mathrm{kN}$. If the friction coefficient increases from 0.02 to 0.07 due to the omission of the lubricant, the process force increases in line with the higher retention forces in the blank holder area. As a result, the rupture threshold of the cup is exceeded, and component failure occurs. The 
numerical results slightly exceed the experimentally determined results, but the deviation is on average less than $10 \%$. If the coefficient of friction in the simulation is increased up to 0.11 (for a standard DLC coating and both polished and millfinish sheet metal), the stamping force exceeds the rupture threshold of the sheet material. At the blank holder, the initial pressure is calculated to be $1.6 \mathrm{MPa}$, while at the drawing radius the maximum contact pressure is about $75 \mathrm{MPa}$.

\section{CONCLUSION}

When using nanoscopically smooth DLC coatings, dry deep drawing tests showed no wear. It was possible to produce up to 53 wear-free cups, whereby the surface quality of the tool remained unchanged and it could still be used without restriction in further tests. The surface roughness of the tool seems to play a major role in the wear development and friction behavior.

While strip drawing tests can accurately simulate dry deep drawing of aluminum with regard to friction and wear, the real deep drawing process must always be designed carefully with consideration of the available process window. In previous investigations, it was possible to carry out wear-free strip drawing tests by means of sheet metal polishing, which showed significantly lower friction than the reference test without coating and native millfinished sheet metal surface. However, if one considers the real deep drawing process and the available process window, sheet polishing alone is insufficient to produce good parts. For this purpose, further friction-reducing measures have to be taken or restrictions regarding the possible drawing ratio have to be accepted.

\section{ACKNOWLEDGEMENTS}

Open Access funding provided by Projekt DEAL. The authors thank the German Research Foundation (DFG) (Grant No. Projekt Number 390892986) for funding of the Project "Functionalizing of a-C:H tool coatings and homogenization of the aluminum passive layer for the dry forming of aluminum" received within the priority program SPP 1676 "Dry metal forming - sustainable production through dry processing in metal forming."

\section{OPEN ACCESS}

This article is licensed under a Creative Commons Attribution 4.0 International License, which permits use, sharing, adaptation, distribution and reproduction in any medium or format, as long as you give appropriate credit to the original author(s) and the source, provide a link to the Creative
Commons licence, and indicate if changes were made. The images or other third party material in this article are included in the article's Creative Commons licence, unless indicated otherwise in a credit line to the material. If material is not included in the article's Creative Commons licence and your intended use is not permitted by statutory regulation or exceeds the permitted use, you will need to obtain permission directly from the copyright holder. To view a copy of this licence, visit http://creativecommons.org/licenses/by/4.0/.

\section{REFERENCES}

1. P. Groche and F. Resch, Materialwiss. Werkst. 46, 813 (2015).

2. M.N. Sharif, S. Pervaiz, and I. Deiab, Int. J. Adv. Manuf. Technol. (2017). https://doi.org/10.1007/s00170-016-9298-5.

3. E. Benedicto, D. Carou, and E.M. Rubio, Proc. Eng. (2017). https://doi.org/10.1016/j.proeng.2017.04.075.

4. O. Pereira, A. Rodríguez, A.I. Fernández-Abia, J. Barreiro, and L.N. López de Lacalle, J. Clean. Prod. (2016). https://d oi.org/10.1016/j.jclepro.2016.08.030.

5. S. Schöler, M. Schmieding, D. Yilkiran, F. Özkaya, C. Nowak, K. Möhwald, B.-A. Behrens, and H.J. Maier, in 16th International Conference on Wear of Materials (2019) http s://doi.org/10.1016/j.wear.2019.01.009.

6. A. Mousavi, K.S. Ridolfi, and A. Brosius, MATEC Web Conf. (2018). https://doi.org/10.1051/matecconf/201819014005.

7. M. Liewald, G.E.M. Tovar, C. Woerz, and G. Umlauf, Int. J. Precis. Eng. Manuf. Green Tech. (2019). https://doi.org/10. 1007/s40684-019-00069-6.

8. K. Bewilogua and D. Hofmann, Surf. Coat. Technol. (2014). https://doi.org/10.1016/j.surfcoat.2014.01.031.

9. T. Abraham, G. Bräuer, F. Kretz, and P. Groche, Dry Met. Form. OAJ FMT 2, 11 (2016).

10. H. Ronkainen, S. Varjus, and K. Holmberg, Wear (1998). https://doi.org/10.1016/S0043-1648(98)00314-7.

11. R. Zhao, J. Steiner, K. Andreas, M. Merklein, and S. Tremmel, Tribol. Int. (2018). https://doi.org/10.1016/j.triboi nt.2017.05.031.

12. C. Donnet and A. Erdemir, Tribology of Diamond-Like Carbon Films (Boston: Springer, 2008).

13. T. Abraham, G. Bräuer, F. Kretz, and P. Groche, MATEC Web Conf. (2018). https://doi.org/10.1051/matecconf/201819 014001.

14. V. Westlund, J. Heinrichs, and S. Jacobson, Tribol. Lett. (2018). https://doi.org/10.1007/s11249-018-1048-4.

15. F. Flegler, S. Neuhäuser, and P. Groche, Tribol. Int. (2020). https://doi.org/10.1016/j.triboint.2019.105956.

16. F. Flegler, P. Groche, T. Abraham, and G. Bräuer, Production at the Leading Edge of Technology: 9th Congress of the German Academic Association for Production Technology (WGP) (2019).

17. K. Taube, Surf. Coat. Technol. (1998). https://doi.org/10.10 16/S0257-8972(97)00178-3.

18. T. Michler and C. Siebert, Surf. Coat. Technol. (2003). https://doi.org/10.1016/S0257-8972(02)00620-5.

19. A. Böge and W. Böge, Handbuch Maschinenbau (Wiesbaden: Springer Fachmedien Wiesbaden, 2014).

Publisher's Note Springer Nature remains neutral with regard to jurisdictional claims in published maps and institutional affiliations. 